\title{
A singularidade da dimensão pictórica em José Luandino Vieira
}

\author{
Pedro Beja Aguiar \\ Dibujar es conocer con la mano \\ (BERger, 2011, p. 87). \\ O olho vê, a lembrança revê, e a imaginação transvê \\ (BARROS, 2013, p. 324).
}

Há um verso de Manoel de Barros no poema "As lições de R.Q." que enuncia: "É preciso transver o mundo" (BARROS, 2013, p. 324). A imagem poética condensada no neologismo transver ajuda a pavimentar um lugar de leitura em que se deseja desenvolver a ideia de que os desenhos do escritor José Luandino Vieira são pensamentos visuais que transfiguram a realidade, escapam do automatismo do cotidiano e deslocam a relação entre palavra e experiência com o intuito de potencializar em pequenos traçados a dinâmica entre linguagem e mundo.

De antemão faz-se necessário explicitar o método que estamos chamando de pensamento visual para que, posteriormente, seja possível delinear as escolhas operacionais de compreensão das imagens. Não simplesmente como uma técnica plástica capaz de esquadrinhar os diferentes processos de criação do autor, esse procedimento apresenta-se como um gesto inaugural - "minha primeira expressão foi plástica" (VIEIRA, 2015, p. 1044) -, um exercício laboral topológico e morfológico de recepção, armazenamento e transcrição de experiências que, ao serem minimamente traçadas numa folha em branco, ganham dimensão narrativa. É, em certa medida, um procedimento semelhante à "mão pensante" formulada por John Berger (2011), em que o desenho tende a ser um diálogo silencioso com a coisa desenhada e pode envolver uma imersão prolongada e total do artista para além de um referencial:

Doutorando do Programa de Pós-Graduação Literatura, Cultura e Contemporaneidade da Pontifícia Universidade Católica do Rio de Janeiro (PUC-Rio), Rio de Janeiro, Brasil. E-mail: pedrobejaaguiar@gmail.com. 
[...] desenhar para descobrir, isto é um processo divino; é encontrar o efeito e a causa. A força da cor não é nada comparada com a força da linha; a linha, que não existe na natureza, mas que expõe e demonstra o tangível com uma definição maior do que a própria visão em relação ao objeto em questão (BERGER, 2011, p. 87).

O modelo referencial para o artista, ainda na leitura de Berger (2011, p. 87), é uma lembrança, um dispositivo de sensações e experiências que ganham forma e volume no processo circunstancial e particular do ato de desenhar. E estas experiências, tateadas pelo processo de estabelecimento de uma marca sobre a folha, são adicionadas à soma total de sua consciência sobre o mundo estrutural tangível, tridimensional. O pensamento pela mão, bem como o pensamento visual que se deseja formular aqui, funciona de maneira semelhante ao processo de ver o mundo pelo deficiente visual, que conhece através da mão, na ausência da luz - de um território dado. Apenas através do tato será possível decodificar minuciosamente um mundo sem codificação anterior. É desenhar para reescrever o mundo partindo de outro lugar. Desta maneira, as duas epígrafes que abrem este texto apresentam o horizonte metodológico de fundo da pesquisa: desenhar, para Luandino Vieira, é uma maneira de materializar, pela superfície do traço, a imaginação.

\section{II}

Na palestra intitulada "A palavra escrita e a não-escrita", proferida em 1983, o escritor italiano Ítalo Calvino promove uma reflexão sobre a "descontinuidade entre a página escrita, fixa e estabelecida, e o mundo móvel e multiforme além da página" (CAlvino, 2006, p. 140). Partindo do incômodo a respeito do que está implicado no espaço de tempo em que o escritor suspende o olhar do texto escrito e o desloca àquilo que o cerca, "este que chamamos atualmente de mundo" (CALvino, 2006, p. 140), Calvino propõe uma chave de leitura sobre a vida cotidiana que esteja atrelada a novas ferramentas, aparelhagens e atitudes:

[...] se sentimos tão intensamente a incompatibilidade entre o escrito e o não-escrito, é porque estamos hoje muito mais cientes do que é o mundo escrito; nunca podemos nos esquecer de que é feito de palavras, de que a linguagem é empregada de acordo com as suas próprias técnicas e estratégias, de que os significados e as relações entre os significados se organizam segundo sistemas especiais (CALVINO, 2006, p. 142).

O momento de suspensão revela um mundo imerso em significações que, inicialmente, limitam e definem o olhar. Portanto, faz-se necessário transver o mundo, conhecê-lo destituído de paradigmas anteriores, colocando em prática o mais simples dos procedimentos: observar os objetos, encará-los nos limites que os integram e, finalmente, transpassá-los. Nesta perspectiva, cabe ao escritor (e a nós, nos limites deste texto) a tarefa de organizar de maneira acessível a recolha de elementos narrativos por meio de um método "o mais trivial e familiar: descrevê-lo 
minuciosamente, como se fosse a coisa mais nova e mais interessante do mundo" (Calvino, 2006, p. 146). Para tanto, como estudo de caso, nos deteremos na leitura de um desenho específico de José Luandino Vieira (FIGURA 1), recolhido do livro Papéis da Prisão: Apontamentos, Diário, Correspondência (1962-1971) (2015), a fim de colocar em prática os procedimentos de análise supracitados mobilizadores das visualidades que compõem o gesto narrativo estético do escritor angolano.

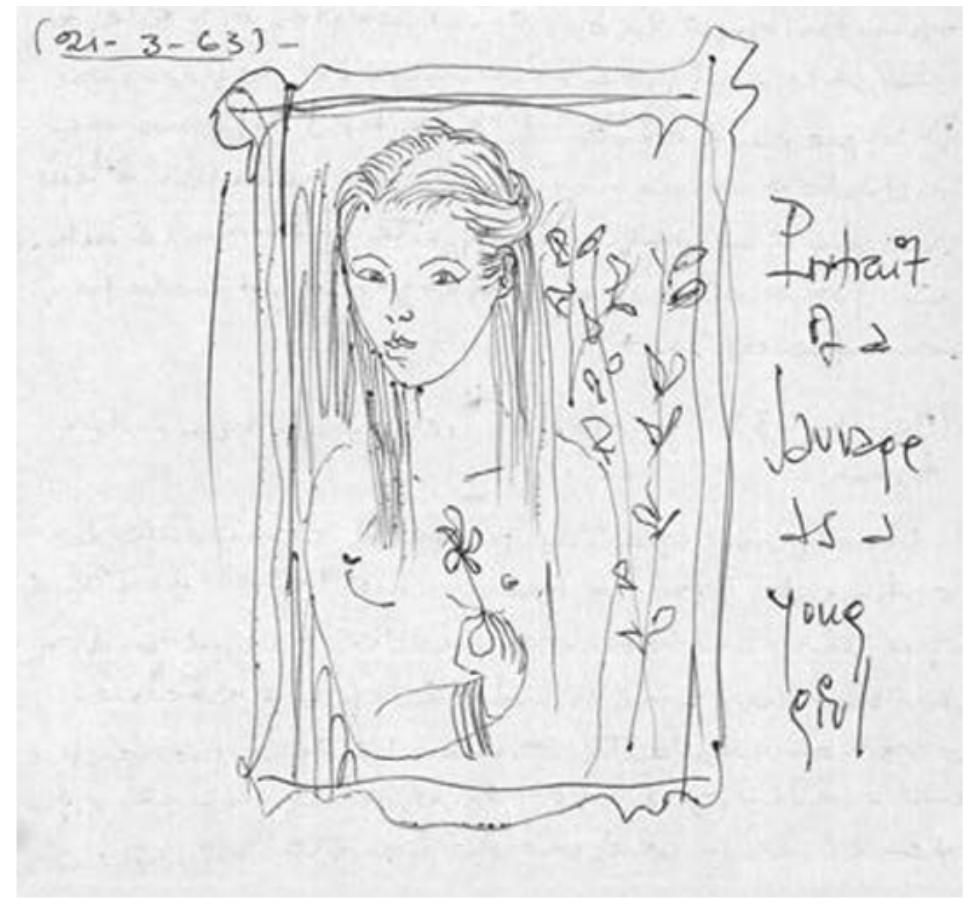

FigurA 1 - Desenho de Luandino Vieira:

Portrait of sauvage as a youg (sic) girl (VIEIRA, 2015, p. 200).

À primeira vista salta aos olhos no desenho "Portrait of a sauvage as a youg [sic] girl” (VIEIRA, 2015, p. 200) um conjunto heterogêneo de informações compondo um mesmo artefato cultural: uma moldura sofisticada; uma personagem feminina desnuda, de cabelos e traços faciais europeus segurando um trevo; um sombreamento ao lado esquerdo da jovem; e uma vegetação semelhante a um tipo de videira ao lado direito - cada um destes elementos materializados pelo estilo particular de Luandino: a dinamicidade dos traços que compõem as linhas, deixandoos mais fortes em um lugar e mais fracos em outro; mais grosso em um pedaço, mais fino em outro; e a escolha deliberada pela incompletude das linhas que produzem o corpo feminino. Em contraste com o desenho evidencia-se a data referente à "21.03.63" - marcador narrativo temporal - e uma legenda composta por palavras em inglês e uma em francês.

Logo chama atenção a cuidadosa centralização do epíteto "sauvage" ("selvagem") ao lado direito do desenho, fora da moldura, dando a entender que o au- 
tor instaura premeditadamente à testemunha ocular (nós) um jogo irônico entre a imagem (o que vemos - o significante) e a palavra (o que ela nos remete como imagem discursiva - o significado). Se nos detivermos aos elementos que compõem a personagem feminina, perceberemos rapidamente que seus traços fogem à caracterização usual da mulher africana.

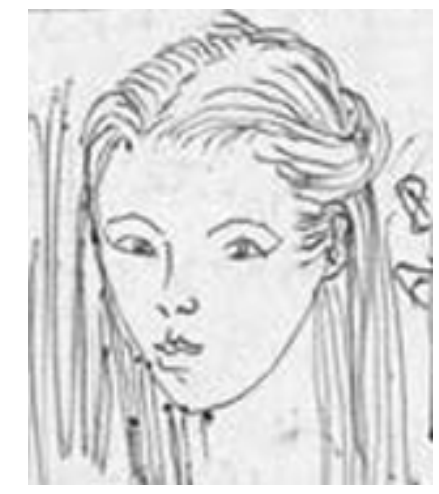

Figura 2 - Excerto de desenho de Luandino Vieira: Portrait of sauvage as a youg (sic) girl (VIEIRA, 2015, p. 200).

Neste caso, vemos uma mulher deificada, endeusada, de estilo europeu (cabelo liso e traços faciais não-negróides). Guardadas as devidas proporções e temporalidades, a sua composição apresenta certa identidade com a pintura da segunda metade do século XIX, que conversa com o realismo e, desta forma, resgata elementos do classicismo. Um exemplo de similaridade se dá com o quadro "Portrait d'une jeune femme" (1470), do pintor flamengo Petrus Christus (FIGURA 3). Neste, somos apresentados a uma mulher colocada numa posição delicada, tridimensional e realista, que olha diretamente para o observador numa expressão circunspecta, porém alerta e capciosa. Os olhos agateados e a leveza no formato do rosto das duas personagens (FIGURA 4), bem como a noção de profundidade, apontam para uma tendência artística da tradição pictórica flamenga de um modelo descritivo que não se limita ao visível enquadrado pelo artista, mas se expande para além dos limites da superfície da pintura/desenho (Schollhammer, 2016, p. 19). Ou seja, há ingenuidade ou certo tom de sedução?

A composição da personagem de José Luandino Vieira não faz parte da representação do mundo africano, mas de uma herança artística europeia. E ela é duplamente enquadrada pelo autor (seja pelo artifício da moldura, seja pelo título que direciona o olhar: "retrato de uma menina selvagem"). Mesmo que seja uma figura desenhada com doçura, com traços singelos na postura e delicadeza no olhar, foilhe imposta uma legenda carregada de significação que a desloca de sentido: o autor joga com a naturalização do olhar colonial na medida em que coloca, em contraste, o paradigma visual e textual da modernidade.

Do imaginário enunciado pelo administrador colonial português por Henrique Galvão, seja no romance $O$ sol dos trópicos (1936) ou no ensaio Antropófagos (1947), 


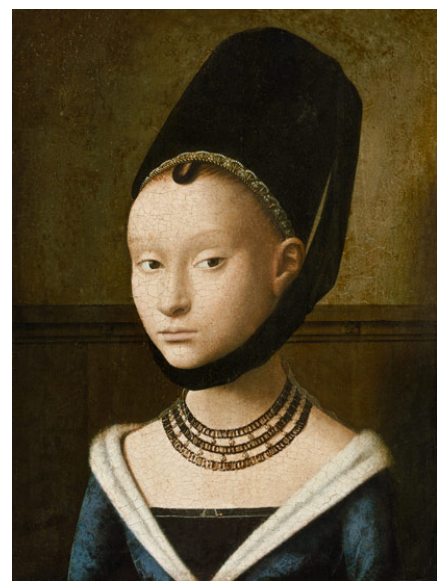

Figura 3 - "Portrait d'une jeune femme" (1470), Petrus Christus.

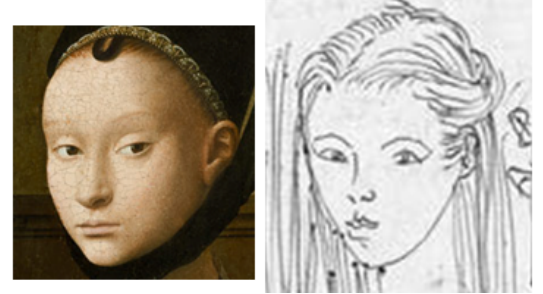

Figura 4 - Excertos da pintura Portrait d'une jeune femme (1470), do pintor flamengo Petrus Christus e do desenho de Luandino Vieira: Portrait of sauvage as a youg (sic) girl (VIEIRA, 2015, p. 200).

e tendo em vista a constituição da Ciência como pilar central da modernidade e sinônimo de um progresso científico e tecnológico que produz e valida conhecimentos e saberes (SANTOS, 2010b) - haja vista a quantidade de instituições ligadas à formação de um "saber colonial" em Portugal desde o final do século XVIII, como demonstra Omar Ribeiro Thomaz (2002, p. 96-99) -, retomamos o desenho de Luandino Vieira: a imagem parece indiciar que o pacto da representação e da constituição do olhar moderno caminha junto com a visão colonial de mundo. A produção de estranhamento que o autor constrói através da ironia do traço da personagem feminina e da justaposição entre imagem e texto produz um incômodo ao observador que o força a desnaturalizar o discurso colonial: apenas as mulheres com traços negróides podem ser categorizadas como selvagens? Ou a alcunha de "selvagem" reside apenas no fato da personagem estar despida?

No ensaio incontornável "Regimes representativos da modernidade", Karl Erik Schollhammer (2016) desenvolve um estudo sobre a relação entre a imagem e o texto, entre a representação visual e a textual, a partir de um campo interdisciplinar conhecido como "Cultura Visual" (visual culture). Da afirmação sobre os domínios da visualidade na recepção estética contemporânea, onde o fascínio pelas imagens possui enorme apelo ao sensível, o autor identifica na relação "entre o que o texto 'faz ver' e o que a imagem 'diz e dá a entender"” (Schollhammer, 2016, p. 11) uma hipótese importante para delinear a arquitetura do regime representativo do momento histórico e cultural moderno:

[...] já não podemos mais tratar a imagem como ilustração da palavra nem o texto como explicação da imagem. É o conjunto texto-imagem que, ao formar um complexo heterogêneo, se torna o objeto fundamental para a compreensão das condições representativas em geral (SCHOLlHAMMER, 2016, p. 16). 
Dentro desta perspectiva, a legenda "selvagem" aponta para três torções de Luandino Vieira sobre a questão colonial que o desenho carrega em si: a constituição de uma moldura refinada que confere valor visual e condensa uma episteme, os elementos de cotejamento no interior do quadro e, por último, a questão de profundidade da personagem feminina, que se desloca da moldura transmitindo a sensação de escape do enquadramento.

\section{III}

Toda moldura é uma saliência que completa, seja para proteger ou para ornamentar, um quadro. Na medida em que enquadra a obra, produz um duplo gesto: direciona o que deve ser visto e delimita o espaço de criação, atribuindo-lhe fronteiras ao mundo externo.

Uma questão de fundo teórica que subjaz as discussões aqui apresentadas tem a ver com a noção de uma mentalidade moderna que se apresenta como visão de mundo e, consequentemente, como um paradigma ainda vigente de hierarquização de saberes. No âmbito da minha pesquisa, esta visada teórica ajuda a pavimentar questões que dialogam frontalmente com o que se propõe pensar aqui de maneira preliminar: as formas plásticas do artista angolano condensam e rasuram tópicos críticos da moldura colonial portuguesa.

À luz das discussões apresentadas pelos teóricos das "epistemologias dos Sul", com especial atenção à Boaventura de Sousa Santos (2010a), Walter Mignolo (2008) e Aníbal Quijano (2005), é possível pensar a modernidade não como uma opção, mas como uma exigência que se apresenta aos espaços periféricos enquanto violência e barbárie, ou seja, que o empreendimento colonial é feito e gerido a pretexto de uma visão de mundo moderna (que suprime valores, tradições, línguas e saberes na medida em que privilegia uma leitura única e universal de mundo). Desta maneira, entendemos que o desenho "Portrait of a sauvage as a youg [sic] girl" (VIEIRA, 2015, p. 200) produz uma torção na visão colonial de mundo a partir do gesto de deslocamento do olhar naturalizado sobre os signos da modernidade, como vimos anteriormente.

Se nos detivermos na moldura do desenho de Luandino Vieira, pensando-a apenas como forma, perceberemos uma estética barroca em sua composição: o excesso de refinamento nas linhas horizontais e verticais regularizadoras dos limites do quadro e a composição rebuscada dos lintéis e das cornijas que lhe conferem efeito clássico. No entanto, se escaparmos à leitura objetiva da moldura como limite e adorno, uma dimensão discursiva do enquadramento sobressai à análise: a moldura funciona como uma metáfora de um paradigma visual, uma referência potente à visão de mundo colonial.

O imperativo da assimilação cultural somado ao rígido sistema do indigenato está presente no desenho de maneira elipsada, nas entrelinhas da composição plástica em contato com os direcionamentos das palavras. Desde a afirmação da diver- 
sidade cultural do império como resultado da força tutelar do Estado, ao mesmo tempo em que se garantia a supremacia do elemento branco, até a postura ambígua no que diz respeito aos ditos mestiços, vistos simultaneamente como representantes de um humanismo que tradicionalmente acompanharia o colonizador lusitano, e como imagem do perigo da sua própria degeneração em terras tropicais - todo o empreendimento discursivo português coexiste nos traços do desenho em análise.

Em síntese, Luandino Vieira condensa na composição da moldura todo um conjunto de dispositivos coloniais como uma prática de gestão política de visualidades, onde a questão cultural (representativa) está no centro do quadro: a personagem feminina se desloca, transmitindo a sensação de escape do enquadramento. Esta é a nossa hipótese: o visível gesto de deslocamento da figura principal faz desmontar a moldura (enquanto forma e paradigma): Luandino Vieira abala os alicerces do mundo colonial a partir das próprias referências deste mundo, torce a moldura colonial naquilo que lhe é mais familiar.

\section{Referências}

BArros, Manoel de. Livro sobre nada. In: Poesia completa. São Paulo: LeYa, 2013. p. 301-327.

Berger, John. Del diário de Janos Lavin. In: Sobre el dibujo. Barcelona: Editorial Gustavo Gili, 2011. p. 87-90.

CAlvino, Ítalo. A palavra escrita e a não-escrita. In: Ferreira, Marieta de M.; AmAdo, Janaína. Usos e abusos da história oral. Rio de Janeiro: FGV, 2006. p. 139-147.

Crosariol, Isabelita Maria. Impérios desmitificados: Ruy Duarte de Carvalho e o passado colonial reescrito. 2009. Dissertação (Mestrado em Letras) - Pontifícia Universidade Católica do Rio de Janeiro, PUC-Rio, 2009. Disponível em: https:// www.maxwell.vrac.puc-rio.br/colecao.php?strSecao=resultado\&nrSeq=14032@1. Acesso em: 2 mar. 2019.

Quijano, Aníbal. Colonialidade do poder, eurocentrismo e América Latina. In: LANDER, E. (org.). A colonialidade do saber: eurocentrismo e ciências sociais: perspectivas latino-americanas. Buenos Aires: CLACSO, 2005. p. 107-130.

Thomaz, Omar Ribeiro. Ecos do Atlântico Sul: representações sobre o terceiro império português. Rio de Janeiro: Editora UFRJ, 2002.

SAntos, Boaventura Sousa. A gramática do tempo: para uma nova cultura política. São Paulo: Cortez Editora, 2006.

SANtos, Boaventura Sousa. Para além do pensamento abissal: das linhas globais a uma ecologia dos saberes. In: SAntos, B. S.; Meneses, M. P. (orgs.). Epistemologias do sul. São Paulo: Cortez, 2010a. p. 30-65.

SANtos, Boaventura Sousa. Um discurso sobre as ciências. São Paulo: Cortez, zo1ob. 
Santos, Jeane de Cassia Nascimento. Descaminhos narrativos: estudo dos romances "O sol dos trópicos" e "O velório d'oiro", de Henrique Galvão e o "Esplendor de Portugal”, de António Lobo Antunes. 2006. Tese (Doutorado em Estudos Comparados de Literaturas de Língua Portuguesa) - Universidade de São Paulo, São Paulo, 2007. Disponível em: https://www.teses.usp.br/teses/disponiveis/8/8156/tde05072007-101424/publico/TESEJEANEDECASSIANASCIMENTOSANTOS.pdf.

Acesso em: 2 mar. 2019.

Schollhammer, Karl Erik. Regimes representativos da modernidade. In: Além do visivel: o olhar da literatura. Rio de Janeiro: 7Letras, 2016. p. 11-39.

Vieira, José Luandino. Papéis Da Prisão: Apontamentos, Diário, Correspondência (1962-1971). Organização de Margarida Calafate Ribeiro, Roberto Vecchi e Mónica V. Silva. Lisboa: Caminho, 2015.

Recebido em 30 de abril de 2019.

Aprovado em 17 de setembro de 2019.

\section{Resumo/Abstract/Resumen}

\section{A singularidade da dimensão pictórica em José Luandino Vieira}

\section{Pedro Beja Aguiar}

Este texto procura formular, de maneira provisória, entendimentos acerca das potencialidades narrativas presentes nas formas plásticas desenvolvidas pelo escritor angolano José Luandino Vieira. A título de estudo de caso, propõe-se analisar o desenho "Portrait of a sauvage as a youg [sic] girl", recolhido do livro Papéis da Prisão (2015), como um gesto narrativo estético que condensa tópicos críticos sobre o empreendimento colonial português e que pavimenta, em pequenos traçados, a relação entre palavra e experiência. Os desenhos aqui são compreendidos não como ilustrações ou rascunhos, mas discurso sobre um método daquilo que definiremos como um pensamento visual.

Palavras-chave: pensamento visual; moldura colonial; colonialidade; modernidade.

The singularity of the pictorial dimension in the works of José Luandino Vieira

\section{Pedro Beja Aguiar}

This text seeks to formulate, provisionally, understandings about the narrative potentialities present in the artistic forms developed by the Angolan writer José Luandino Vieira. This case study aims to analyse the drawing "Portrait of a sauvage as a youg [sic] girl", collated in the book Papéis da Prisão (2015), with an aesthetic 
narrative gesture that condenses critical topics regarding the Portuguese colonial enterprise and that covers, in small steps, the relationship between word and experience. The drawings here are understood not as illustrations or sketches, but rather as a discourse on a method which we will define as visual thought.

Keywords: visual thinking, colonial setting, colonialism, modernity.

\section{La singularidad de la dimensión pictórica en José Luandino Vieira}

\section{Pedro Beja Aguiar}

Este texto busca formular, de manera provisional, cierta comprensión sobre las potencialidades narrativas presentes en las formas plásticas desarrolladas por el escritor angoleño José Luandino Vieira. En este estudio de caso, se propone analizar el dibujo "Portrait of a sauvage as a youg [sic] girl", recogido en el libro $\mathrm{Pa}$ péis da Prisão (2015), como un gesto narrativo estético que condensa tópicos críticos sobre la empresa colonial portuguesa y que pavimenta, con pequeños trazos, la relación entre la palabra y la experiencia. Los dibujos son comprendidos aquí no como ilustraciones o borradores, sino como un discurso sobre un método de lo que definiremos como pensamiento visual.

Palabras clave: pensamiento visual, marco colonial, colonialidad, modernidad. 